\title{
Dynamic Mechanical Study of Block Copolymer Crystallization Confined within Spherical Nanodomains
}

\author{
By Shuichi NOJIMA, ${ }^{1, *}$ Daisuke INOKAWA, ${ }^{1}$ Takanobu KAWAMURA, ${ }^{2}$ and Koh-hei NITTA ${ }^{2}$
}

We have measured the thermal and dynamic mechanical properties of a crystalline-amorphous diblock copolymer, poly $(\varepsilon-$ caprolactone)-block-polybutadiene (PCL- $b$-PB), in which the crystallization of PCL blocks was completely confined within spherical domains. DSC results showed that the crystallization behavior of PCL blocks was substantially different from that of crystalline homopolymers, and similar to that usually observed in other spherically confined crystalline blocks. The result of dynamic mechanical measurements clearly showed that the crystallization within each domain occurred independently to immediately yield crystallized rigid domains, indicating that crystal nucleation drives the total crystallization in this system. It is demonstrated that the dynamic mechanical measurement is an alternative method to pursue the spherically confined crystallization.

KEY WORDS: Crystalline-amorphous Diblock Copolymer / Spherical Nanodomain / Confined Crystallization / Dynamic Mechanical

Measurements /

Crystalline-amorphous diblock copolymers show a unique crystallization behavior when they are quenched from a microphase-separated melt into low temperatures. It is well known that two kinds of crystallized morphology are formed in the system depending on the segregation strength of existing microdomain structures, mobility (or glass transition) of amorphous blocks, or crystallization rate (or degree of supercooling). ${ }^{1,2}$ When the microdomain structure is not stable against the crystallization, it is replaced by a lamellar morphology, an alternating structure consisting of lamellar crystals and amorphous layers, in which the amorphous blocks are sandwiched between lamellar crystals. ${ }^{3,4}$ When the microdomain structure is enough stable against the crystallization, on the other hand, it is completely preserved through the crystallization process to yield a crystallized microdomain structure. ${ }^{5,6}$

When crystalline blocks form (strongly segregated) spherical domains surrounded by amorphous blocks in high molecular weight diblocks, they crystallize within it. The crystallization behavior and resulting morphology for this case have extensively been studied so far ${ }^{5-17}$ mainly by small-angle X-ray scattering (SAXS) and/or differential scanning calorimetry (DSC) techniques. The crystallization behavior was found to be extremely different from that of crystalline homopolymers; the crystallinity development did not show a sigmoid change usually observed in homopolymer crystallization with increasing crystallization time $t_{\mathrm{c}}$. Alternatively it was reasonably approximated by a first-order kinetics, that is, the crystallization rate was proportional to the volume fraction of uncrystallized blocks existing in the system at $t_{\mathrm{c}}$. These experimental facts lead to a conclusion that the crystallization occurs independently within each domain. Therefore, the nucleation in individual domain drives the total crystallization process, because the crystal growth is considered to be extremely fast.

Reiter et al. directly confirmed this conclusion by using atomic force microscope (AFM) during the confined crystallization of poly(ethylene oxide) (PEO) blocks in PEO- $b$ poly(butadiene- $b$-ethylene oxide) (PEO- $b$-PB). ${ }^{18}$ They showed that the crystallization and melting within each domain occur individually and independently from AFM pictures taken as a function of $t_{\mathrm{c}}$ during crystallization or temperature during heating. Later AFM techniques were used for the break-out crystallization as well as the confined crystallization in crystalline-amorphous diblocks. ${ }^{19-22}$

AFM results provide direct information on the crystallization at sampled points, while SAXS and DSC techniques supply average information over the whole systems. In addition, it is necessary for the understanding of crystallization to analyze the crystallization process by using some method developed for homopolymer crystallization. Avrami analysis, for example, is a typical method for the analysis of early stage crystallization in homopolymers. However, these techniques are advantageous for comprehensive and quantitative understanding for the crystallization behavior of bulk samples.

In this study, we try to observe the crystallization behavior of spherically confined crystalline blocks by using a dynamic mechanical measurement, which again provides average information on the crystallization behavior of bulk copolymers. From experimental results we clarify the crystallization mechanism of this system, and also show that the dynamic mechanical measurement is an alternative method to observe

\footnotetext{
${ }^{1}$ Department of Organic and Polymeric Materials, Graduate School of Science and Engineering, Tokyo Institute of Technology, $\mathrm{H}-125$, 2-12-1 Ookayama, Meguro-Ku, Tokyo 152-8552, Japan

${ }^{2}$ Department of Chemical Engineering, Graduate School of Natural Science \& Technology, Kanazawa University, Kakuma-cho Kanazawa 920-1192, Japan

*To whom correspondence should be addressed (Tel: +81-3-5734-2132, Fax: +81-3-5734-2888, E-mail: snojima@ polymer.titech.ac.jp).
} 
Table I.

\begin{tabular}{ccccccc}
\hline \multirow{2}{*}{ Sample Code } & $M_{\mathrm{n}}{ }^{\mathrm{a}}$ & $M_{\mathrm{w}} / M_{\mathrm{n}}{ }^{\mathrm{b}}$ & ${\mathrm{PCL}: \mathrm{PB}^{\mathrm{c}}}$ & $R_{\mathrm{d}}{ }^{\mathrm{d}}$ & $R_{\mathrm{s}}{ }^{\mathrm{e}}$ & $T_{\mathrm{m}}{ }^{\mathrm{f}}$ \\
\cline { 2 - 7 } & $(\mathrm{g} / \mathrm{mol})$ & & $($ vol. \%) & $(\mathrm{nm})$ & $(\mathrm{nm})$ & $\left({ }^{\circ} \mathrm{C}\right)$ \\
\hline $\mathrm{B} 125$ & 125,000 & 1.10 & $18: 82$ & 18.0 & 17.0 & 49 \\
$\mathrm{hPCL}^{\mathrm{g}}$ & 11,000 & 1.18 & $100: 0$ & - & - & 55 \\
\hline
\end{tabular}

a Determined by membrane osmometry. bDetermined by GPC. ${ }^{c}$ Determined by ${ }^{1} \mathrm{H}$ NMR. ${ }^{\mathrm{d}}$ Calculated from the angular position of SAXS primary peak and $\mathrm{PCL}$ volume fraction. ${ }^{\mathrm{e}}$ Calculated from the angular

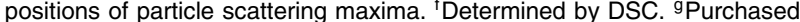
from Polymer Source Inc., and molecular parameters are provided by the manufacturer.

the block copolymer crystallization confined within spherical domains.

\section{EXPERIMENTAL}

\section{Samples and Sample Preparation}

A poly( $\varepsilon$-caprolactone)-block-polybutadiene (PCL- $b$-PB) diblock copolymer (B125) was synthesized by a successive anionic polymerization under vacuum. Details of this synthesis and subsequent purification have already been described. ${ }^{23,24}$ The molecular characteristics of PCL- $b$-PB, together with PCL homopolymer (hPCL) used for DSC measurements, are shown in Table I. The volume fraction of PCL blocks was adjusted to be enough small $(=0.18)$ so as to form the spherical microdomain structure in the melt. The radius of PCL spheres in the melt was evaluated from the SAXS peak position and independently from the particle scattering of isolated spheres.

The PCL block could crystallize at temperatures below $-40^{\circ} \mathrm{C}^{6}$ and the melting was observed at above $45^{\circ} \mathrm{C}$ (Table I). Therefore it did not further crystallize nor melt at room temperature, and kept initial crystallinity for a long time. This fact made it possible to prepare B125 with various PCL crystallinities ranging from 0 to 0.45 (maximum crystallinity) by holding B125 at a low temperature $\left(\sim-50{ }^{\circ} \mathrm{C}\right)$ for different prescribed times $t_{\mathrm{c}}$ and subsequently bringing it into room temperature. Eventually the parameters characterizing the crystallization process at $-50{ }^{\circ} \mathrm{C}$ were evaluated as a function of $t_{\mathrm{c}}$ (or crystallinity) by heating each B125 from room temperature up to $70^{\circ} \mathrm{C}$.

\section{SAXS Measurements}

The microdomain structure before and after the crystallization of PCL blocks was observed by small-angle X-ray scattering with synchrotron radiation (SR-SAXS), which was performed at Photon Factory in high energy accelerator research organization, Tsukuba Japan, with a small-angle $\mathrm{X}$-ray equipment for solution (SAXES) installed at beam-line BL-10C. Details of the equipment and the instrumentation are described in our previous publications. ${ }^{25-27}$ The SR-SAXS curves measured were corrected for background scattering and absorption by the sample, but not for the smearing effect because SAXES employed a point focusing optics. The SAXS curves were finally obtained as a function of $s$ defined by $s=(2 / \lambda) \sin \theta$, where $2 \theta$ is the scattering angle and $\lambda$ is the $\mathrm{X}$-ray wavelength $(=0.1488 \mathrm{~nm})$.

\section{DSC Measurements}

A Perkin Elmer DSC Diamond was used with a heating rate of $10^{\circ} \mathrm{C} / \mathrm{min}$ to obtain the melting temperature $T_{\mathrm{m}}$ and crystallinity $\chi\left(t_{\mathrm{c}}\right)$ of PCL blocks isothermally crystallized at $-50{ }^{\circ} \mathrm{C}$ for $t_{\mathrm{c}} . T_{\mathrm{m}}$ was defined as the temperature at which the endothermic peak was a maximum and $\chi\left(t_{\mathrm{c}}\right)$ was calculated from the endothermic peak area $\Delta H\left(t_{\mathrm{c}}\right)$ by,

$$
\chi\left(t_{\mathrm{c}}\right)=\Delta H\left(t_{\mathrm{c}}\right) /\left(\Delta H^{\circ} w_{\mathrm{PCL}}\right)
$$

where $\Delta H^{\circ}$ is the heat of fusion for perfect PCL crystals $(=135.44 \mathrm{~J} / \mathrm{g})^{28}$ and $w_{\mathrm{PCL}}$ is the weight fraction of PCL blocks in B125. The change of $T_{\mathrm{m}}$ and $\chi\left(t_{\mathrm{c}}\right)$ against $t_{\mathrm{c}}$ was finally obtained from DSC results.

\section{Dynamic Mechanical Measurements}

The dynamic mechanical properties were measured by a dynamic mechanical analyzer (Rheology Co. Ltd., DVE V-4). Details of measurements were already described. ${ }^{29}$ The size of rectangular specimens was $15 \mathrm{~mm}$ (length) $\times 5 \mathrm{~mm}$ (width) $\times$ ca. $0.5 \mathrm{~mm}$ (thickness). The measurements were made at a constant frequency of $10 \mathrm{~Hz}$ with a constant oscillationamplitude of $6 \mu \mathrm{m}$. The storage tensile modulus $E^{\prime}$, loss modulus $E^{\prime \prime}$, and loss tangent $\tan \delta$ were derived during heating from $30^{\circ} \mathrm{C}$ up to $70^{\circ} \mathrm{C}$ at a constant rate $\left(\sim 2{ }^{\circ} \mathrm{C} / \mathrm{min}\right)$ under nitrogen atmosphere, and finally each value was obtained as a function of temperature.

\section{RESULTS AND DISCUSSION}

\section{Microdomain Structure Observed by SAXS}

Figure 1 shows the SAXS curves of B125 at amorphous $\left(\sim 70{ }^{\circ} \mathrm{C}\right)$ and fully crystallized $\left(\chi(\infty) \equiv \chi_{\max } \sim 0.45\right)$ states. We have a strong intensity peak on both SAXS curves but higher-order peaks are not observed. Judging from the volume fraction of PCL blocks in the system (Table I) together with the SAXS intensity peak observed at the melt, we conclude that a spherical microdomain structure is formed in the amorphous state. This structure was also confirmed by transmission electron microscopy (TEM) (results not shown here).

The angular position of the primary intensity peak does not shift at all after the crystallization of PCL blocks, indicating that the spherical domains are completely preserved during the crystallization process and eventually PCL blocks crystallize within these domains. We can also observe a significant difference in the SAXS curves at the higher $s$ range; amorphous B125 shows intensity bumps (indicated by arrows in Figure 1) arising from the particle scattering, while crystallized B125 has a diffuse shoulder over the wide $s$ range instead of intensity bumps. This difference will be attributed to the distortion of PCL domains by the crystallization inside. ${ }^{13}$

The average radius of PCL domains was evaluated from the SAXS peak position $\left(R_{\mathrm{d}}\right.$ in Table $\left.\mathrm{I}\right)$ and independently from the particle scattering $\left(R_{\mathrm{S}}\right){ }^{6}$ and results are shown in Table I. Two values agree satisfactorily with each other $(17-18 \mathrm{~nm})$, which also confirms that the spherical microdomain structure is formed in the system. Therefore, we can expect the confined 


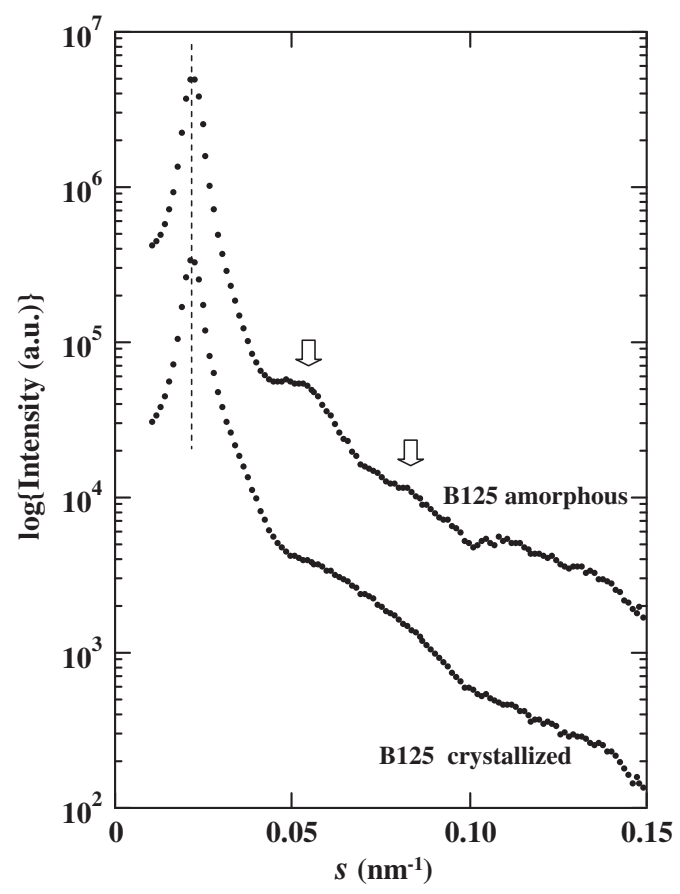

Figure 1. SAXS curves before and after the crystallization of PCL blocks in B125. The curve for amorphous B125 is shifted upward for legibility.

crystallization of PCL blocks within nanodomains, and this crystallization behavior was evaluated from the heating process of B125 with various crystallinities by DSC and independently by dynamic mechanical measurements.

\section{Thermal Properties Measured by DSC}

Figure 2 shows $\chi\left(t_{\mathrm{c}}\right)$ and $T_{\mathrm{m}}$ of hPCL (a) and PCL blocks in B125 (b) as a function of crystallization time $t_{\mathrm{c}}$. In the crystallization of hPCL, both $\chi\left(t_{\mathrm{c}}\right)$ and $T_{\mathrm{m}}$ increase steadily with increasing $t_{\mathrm{c}}$ at the late stage $\left(t_{\mathrm{c}}>5 \mathrm{~min}\right)$. The increase of these values is known to be linear in a semi-logarithmic plot for usual crystalline homopolymers, ${ }^{30,31}$ which is attributed to the lamella thickening during the late stage crystallization. ${ }^{32}$ In addition, the well-known Avrami plot at the early stage gave the Avrami index of $c a .3$ at every crystallization temperature, indicating that a combined mechanism of crystal nucleation and growth is working during homopolymer crystallization.

The $t_{\mathrm{c}}$ dependence of $\chi\left(t_{\mathrm{c}}\right)$ and $T_{\mathrm{m}}$ for PCL blocks in B125 is extremely different from that of hPCL. That is, $\chi\left(t_{\mathrm{c}}\right)$ does not show a sigmoid development but show a steep increase at the early stage without any detectable induction time followed by an asymptotical increase at the late stage. In addition, $T_{\mathrm{m}}$ is almost constant irrespective of $t_{\mathrm{c}}$. The increase of $\chi\left(t_{\mathrm{c}}\right)$ can be successfully explained by the first-order kinetics; the crystallization rate is proportional to the volume fraction of uncrystallized region existing in the system at $t_{\mathrm{c}}$, and therefore the plot of $\ln \left\{1-\tilde{\chi}\left(t_{\mathrm{c}}\right)\right\}$ against $t_{\mathrm{c}}$ should be linear, ${ }^{5,33,34}$ where $\tilde{\chi}\left(t_{\mathrm{c}}\right)$ is the normalized crystallinity of PCL blocks at $t_{\mathrm{c}}$ (i.e., $\left.\tilde{\chi}\left(t_{\mathrm{c}}\right)=\chi\left(t_{\mathrm{c}}\right) / \chi(\infty)\right)$. Indeed, this plot was linear, indicating that the crystallization of PCL blocks is successfully explained by the first-order kinetics.

The crystallization behavior shown in Figure $2 \mathrm{~b}$ is completely consistent with other experimental results reported for crystalline-amorphous diblocks with spherical domains. ${ }^{5,6,18}$ In these reports, this crystallization is explained comprehensively by the nucleation-controlled mechanism within each domain, that is, once the nucleation occurs the crystal growth should be instantaneous because the growth finishes within each domain. In the next section, we observe this crystallization process by dynamic mechanical measurements to confirm the conclusion derived by DSC methods.

\section{Crystallization Behavior Observed by Dynamic Mechanical Measurements}

Theoretical Prediction. Before showing the experimental results of dynamic mechanical measurements, we predict the $\chi\left(t_{\mathrm{c}}\right)$ dependence of storage tensile modulus $E^{\prime}$ in our system, which will intimately depend on the crystallization behavior of PCL blocks confined in nanodomains surrounded by PB matrices. For this purpose, we propose three different models describing the crystallization behavior of PCL blocks.
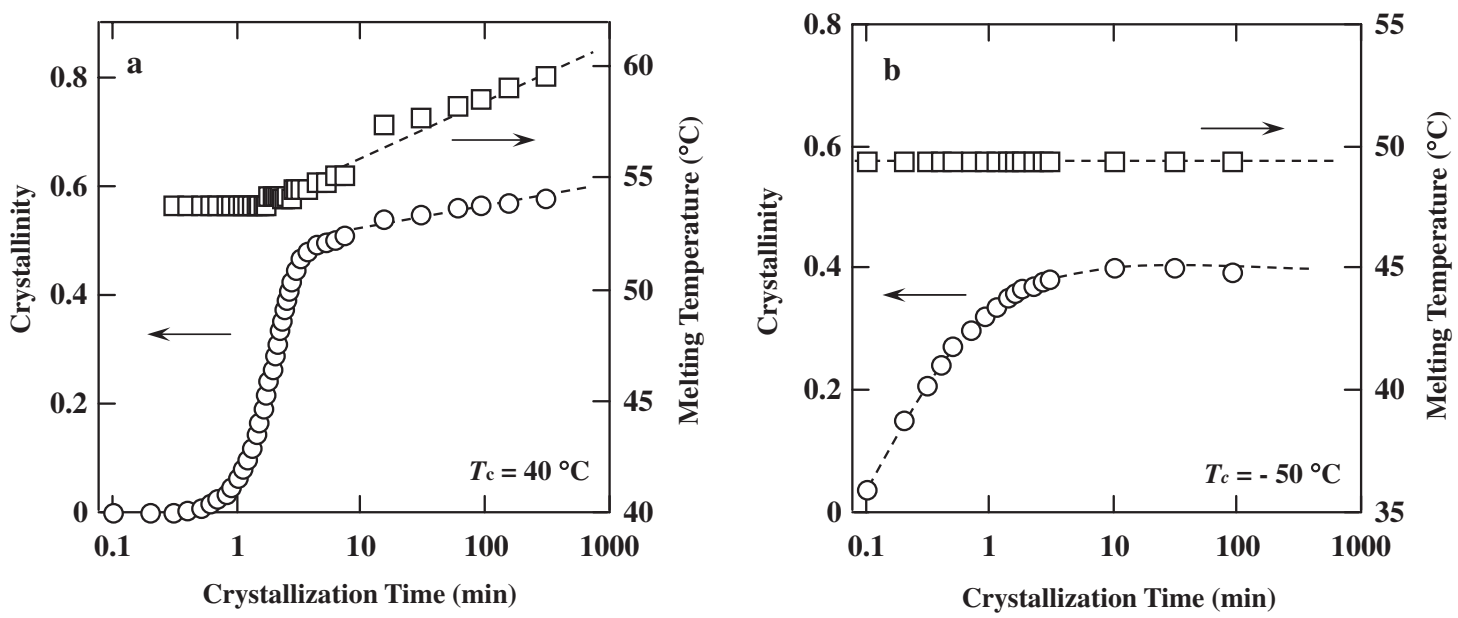

Figure 2. Crystallinity and melting temperature of PCL chains plotted against crystallization time for $h P C L$ (a) and B125 (b). 
Halpin and Tsai proposed a general equation to predict $E^{\prime}$ for such a system in which rigid phases are homogeneously dispersed without any interaction among them, ${ }^{35-37}$

$$
\frac{E^{\prime}}{E_{0}^{\prime}}=\frac{1+A B \phi}{1-B \Psi \phi}
$$

and

$$
B=\frac{E_{2}^{\prime} / E_{0}^{\prime}-1}{E_{2}^{\prime} / E_{0}^{\prime}+A}
$$

where $E_{0}^{\prime}$ and $E_{2}^{\prime}$ are $E^{\prime}$ values of the matrix and rigid phase, respectively, $A$ is related to the factors such as the geometry of rigid phases and the Poisson ratio of matrices and approximated to be 1.5 when the matrix is incompressible, $\Psi$ is a constant representing the packing geometry of rigid phases and we simply put $\Psi=1$ in our system, and $\phi$ is the volume fraction of rigid phases existing in the system. We can predict the $\chi\left(t_{\mathrm{c}}\right)$ dependence of $E^{\prime}$ by assuming that $\phi$ (for Model 1) or $E^{\prime}{ }_{2}$ (for Model 2 or Model 3) changes as a function of $\chi\left(t_{\mathrm{c}}\right.$ ).

In Model 1, we assume that PCL blocks in each domain crystallize independently as reported for many crystallineamorphous diblocks, and also that once the crystallization starts the domain becomes rigid immediately to have $\chi_{\max }$. In this case, the volume fraction of crystallized domains $\phi$ at $t_{\mathrm{c}}$ can be written as,

$$
\phi=\left\{\chi\left(t_{\mathrm{c}}\right) / \chi_{\max }\right\} \phi_{2}
$$

where $\phi_{2}$ is the volume fraction of PCL domains existing in the whole system. In addition, each crystallized domain has a constant $E^{\prime}\left(=E_{2}^{\prime}\right)$ represented by

$$
E_{2}^{\prime}=\chi_{\max } E_{\mathrm{c}}^{\prime}+\left(1-\chi_{\max }\right) E_{\mathrm{PCL}}^{\prime}
$$

where $E^{\prime}{ }_{\mathrm{c}}$ is $E^{\prime}$ of PCL crystals and $E_{\mathrm{PCL}}^{\prime}$ is that of amorphous PCL and equal to $E_{\mathrm{PB}}^{\prime}$ ( $E^{\prime}$ of amorphous $\mathrm{PB}$ matrix). Consequently, we assume that the rigid (or crystallized) spheres with $E_{2}^{\prime}$ increase gradually with increasing $\chi\left(t_{\mathrm{c}}\right)$. Eq 2 is finally re-written as,

$$
\frac{E^{\prime}}{E_{\mathrm{PB}}^{\prime}}=\frac{2.5+(k-1)\left\{\chi_{\max }+1.5 \phi_{2} \chi\left(t_{\mathrm{c}}\right)\right\}}{2.5+(k-1)\left\{\chi_{\max }-\phi_{2} \chi\left(t_{\mathrm{c}}\right)\right\}}
$$

where $k=E^{\prime}{ }_{\mathrm{c}} / E_{\mathrm{PB}}^{\prime}(\gg 0)$, that is, the ratio of $E^{\prime}$ for PCL crystals and $\mathrm{PB}$ matrices.

In Model 2, we assume that the crystallization starts simultaneously at all domains (i.e., $\phi=\phi_{2}=$ const. in eq 2), and that the crystal growth drives the whole crystallization process. That is, once the crystallization starts, $E_{2}^{\prime}$ of all domains changes by

$$
E_{2}^{\prime}=\chi\left(t_{\mathrm{c}}\right) E_{\mathrm{c}}^{\prime}+\left\{1-\chi\left(t_{\mathrm{c}}\right)\right\} E_{\mathrm{PCL}}^{\prime}
$$

Eq 2 can be written in this case as,

$$
\frac{E^{\prime}}{E_{\mathrm{PB}}^{\prime}}=\frac{2.5+(k-1)\left(1+1.5 \phi_{2}\right) \chi\left(t_{\mathrm{c}}\right)}{2.5+(k-1)\left(1-\phi_{2}\right) \chi\left(t_{\mathrm{c}}\right)}
$$

This model means that the rigidity of every domain increases with increasing $\chi\left(t_{\mathrm{c}}\right)$ according as eq 7 .

In Model 3, we assume that the crystallization occurs simultaneously at all domains but instead of eq 7 the $\chi\left(t_{\mathrm{c}}\right)$ dependence of $E_{2}^{\prime}$ is given by Takayanagi's model, ${ }^{38}$

$$
E_{2}^{\prime}=\frac{\chi_{\max }}{\left(\frac{\chi\left(t_{\mathrm{c}}\right)}{\chi_{\max }}\right) E_{\mathrm{c}}^{\prime-1}+\left(1-\frac{\chi\left(t_{\mathrm{c}}\right)}{\chi_{\max }}\right) E_{\mathrm{PCL}}^{\prime-1}}+\left(1-\chi_{\max }\right) E_{\mathrm{PCL}}^{\prime}
$$

which indicates that the viscosity of crystallized domains controls their mechanical properties until $\chi\left(t_{\mathrm{c}}\right)$ reaches to $\chi_{\max }$. Eq 2 is written as,

$$
\frac{E^{\prime}}{E_{\mathrm{PB}}^{\prime}}=\frac{2.5+\frac{(k-1)\left(1+1.5 \phi_{2}\right) \chi\left(t_{\mathrm{c}}\right)}{\chi\left(t_{\mathrm{c}}\right) / \chi_{\max }+k\left\{1-\chi\left(t_{\mathrm{c}}\right) / \chi_{\max }\right\}}}{2.5+\frac{(k-1)\left(1-\phi_{2}\right) \chi\left(t_{\mathrm{c}}\right)}{\chi\left(t_{\mathrm{c}}\right) / \chi_{\max }+k\left\{1-\chi\left(t_{\mathrm{c}}\right) / \chi_{\max }\right\}}}
$$

We tried several other models for $E_{2}^{\prime}$ (instead of eqs 7 or 9) to predict the $\chi\left(t_{\mathrm{c}}\right)$ dependence of $E^{\prime}$, for example, eq 2 was again applied to the crystallized domain to get $E_{2}^{\prime}$. However, every model resulted in the similar $\chi\left(t_{\mathrm{c}}\right)$ dependence of $E^{\prime}$ predicted by Model 2 (eq 7) or Model 3 (eq 9). This is a reasonable conclusion as long as we use the assumption that the crystallization starts simultaneously at all domains.

We put $\phi_{2}=0.18$ (Table I), $\chi_{\max }=0.45$ (DSC results), and $k=100,1000$, and 10000, and showed the $\chi\left(t_{\mathrm{c}}\right)$ dependence of $E^{\prime} / E_{\mathrm{PB}}^{\prime}$ in Figure 3 for three models. In Model 1, we find that $E^{\prime} / E_{\mathrm{PB}}^{\prime}$ increases almost linearly with increasing $\chi\left(t_{\mathrm{c}}\right)$, which arises from the fact that once the crystallization of PCL blocks occurs in the domains they become rigid immediately to yield the gradual increase of rigid spheres in the system with increasing $t_{\mathrm{c}}$. In Model 2, we assume that the crystallization starts simultaneously at all domains and they get hard at the early stage crystallization (by eq 7) to result in a sudden increase in $E^{\prime} / E_{\mathrm{PB}}^{\prime}$ at small $\chi\left(t_{\mathrm{c}}\right)$. In Model 3, we assume again that the crystallization occurs simultaneously at all domains but they do not harden until $\chi\left(t_{\mathrm{c}}\right)$ reaches to $\chi_{\max }$. Therefore, $E^{\prime} / E_{\mathrm{PB}}^{\prime}$ increases slightly when $\chi\left(t_{\mathrm{c}}\right)$ is small.

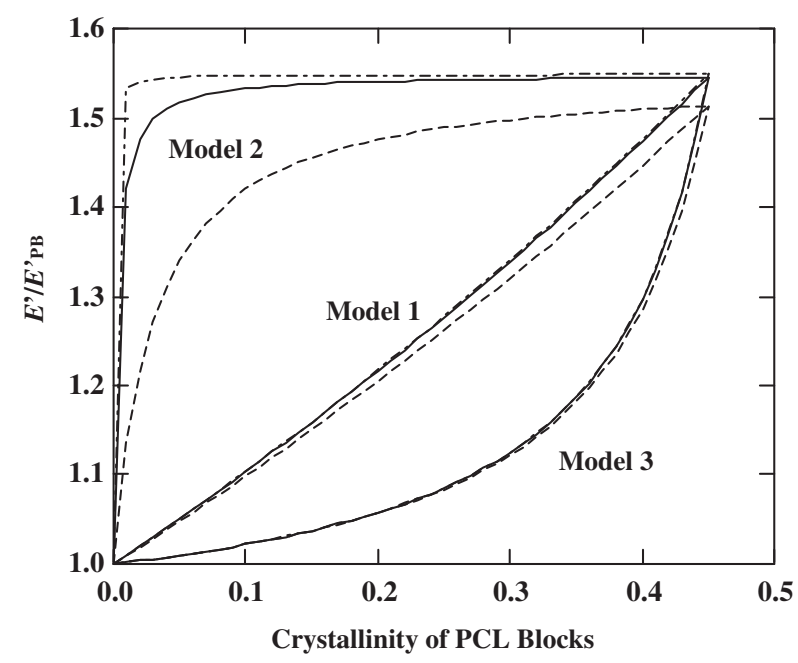

Figure 3. Calculated $E^{\prime} / E_{\mathrm{PB}}^{\prime}$ for Model 1, Model 2, and Model 3 plotted against the crystallinity of PCL blocks: -..--: $k=100$ ․ $k=1000,-\cdots:---10000$. 


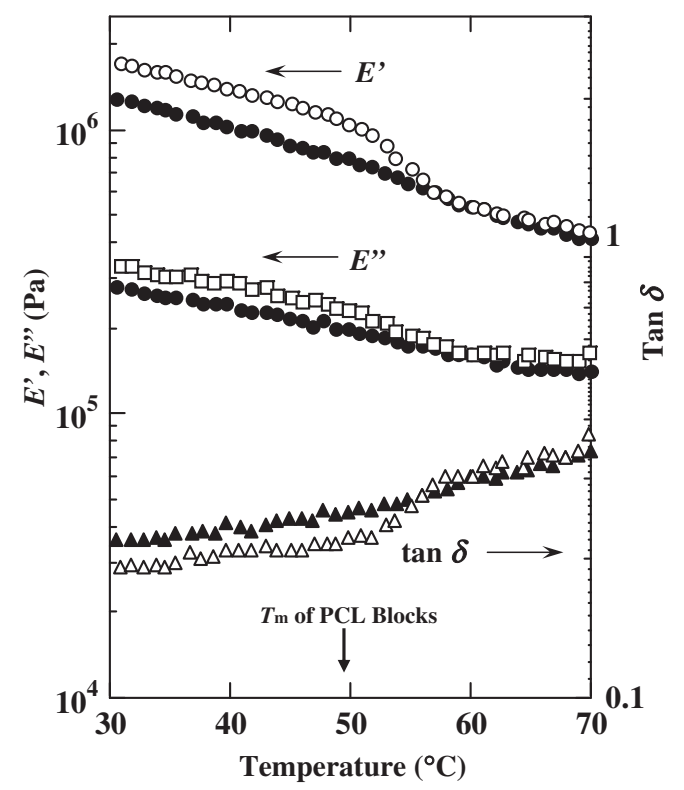

Figure 4. $E^{\prime}, E^{\prime \prime}$ and $\tan \delta$ for amorphous B125 (closed symbols) and crystallized B125 with $\chi_{\max }$ (open symbols) plotted against temperature during heating at $2{ }^{\circ} \mathrm{C} / \mathrm{min}$.

We can find from Figure 3 that the $\chi\left(t_{\mathrm{c}}\right)$ dependence of $E^{\prime} / E_{\mathrm{PB}}^{\prime}$ is not entirely affected by the choice of $k$ but significantly affected by the models we assumed. Therefore, it will be possible which model is reasonable to describe the crystallization behavior of spherically confined PCL blocks by measuring the $\chi\left(t_{\mathrm{c}}\right)$ dependence of $E^{\prime} / E_{\mathrm{PB}}^{\prime}$.

Comparison with Experimental Results. Figure 4 shows the temperature dependence of $E^{\prime}, E^{\prime \prime}$, and $\tan \delta$ for amorphous B125 $\left(\chi\left(t_{\mathrm{c}}\right)=0\right.$, closed symbols) and B125 with $\chi\left(t_{\mathrm{c}}\right)=0.45$ (open symbols) measured during heating at a constant rate of $2{ }^{\circ} \mathrm{C} / \mathrm{min}$. The decreasing (or increasing) rate of these values for crystallized B125 changes at around $T_{\mathrm{m}}$ (indicated by an arrow on the abscissa). In particular, this change is clear in the plot of $E^{\prime} v s$. temperature, and the onset of this change exactly corresponds to $T_{\mathrm{m}}$ measured by DSC. On the other hand, the amorphous B125 shows no characteristic changes in the decreasing rate of $E^{\prime}$ and $E^{\prime \prime}$ and they decrease monotonously over the whole temperature range measured. This is easily expected because no phase transition can be expected for the amorphous B125 over the temperature range investigated.

Figure 5 shows the experimental result of $E^{\prime} / E_{\mathrm{PB}}^{\prime}$ at $45^{\circ} \mathrm{C}$ plotted against $\chi\left(t_{\mathrm{c}}\right)$ (open circle), where the theoretical predictions for three models with $k=1000$ are also depicted by solid curves. It is clearly understood that the experimental result satisfactorily follows the prediction based on Model 1, that is, each domain crystallizes individually to yield rigid spheres immediately. Therefore our results of dynamic mechanical measurements suggest the first-order kinetics for the crystallization of PCL blocks confined within the spherical domains, which is the same conclusion derived by DSC results for B125 and also consistent with the conclusion derived by SAXS, DSC, or AFM techniques for other spherically confined

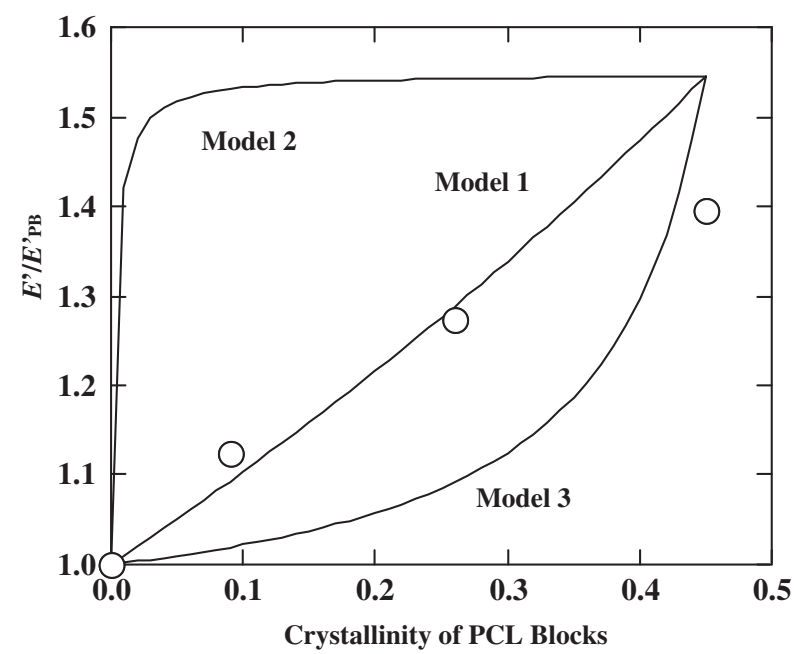

Figure 5. Experimental $E^{\prime} / E_{P B}^{\prime}$ at $45^{\circ} \mathrm{C}$ plotted against the crystallinity of PCL blocks. The solid curves represent the crystallinity dependence of $E^{\prime} / E^{\prime}{ }_{P B}$ calculated based on each model by putting $k=1000$.

(a) Crystallization Confined within Nanodomains

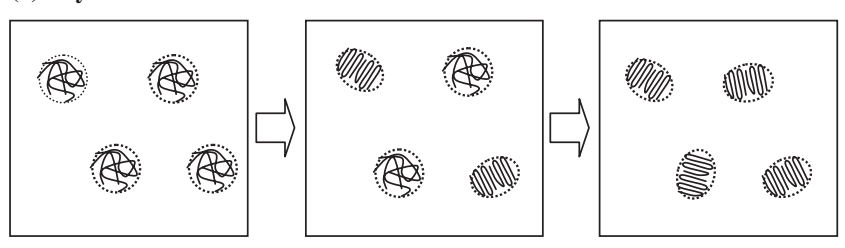

(b) Model of Confined Crystallization for Dynamic Mechanical Properties

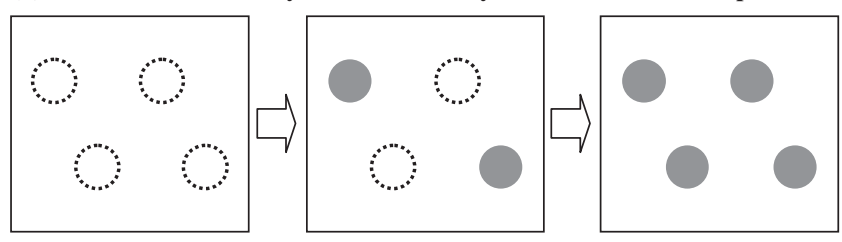

Figure 6. (a) Schematic illustration showing the confined crystallization within spherical domains. (b) Equivalent model of confined crystallization to explain the $\chi\left(t_{\mathrm{c}}\right)$ dependence of dynamic mechanical properties.

crystalline blocks. Figure 6a shows a schematic illustration of spherically confined crystallization in our system and Figure $6 \mathrm{~b}$ indicates the equivalent model for this crystallization to explain the $\chi\left(t_{\mathrm{c}}\right)$ dependence of dynamic mechanical properties.

We think this is the first time to show that dynamic mechanical measurements are an alternative method to investigate the crystallization process of bulk samples, in which the crystalline components are completely confined in the isolated domain and the crystallization occurs within it. Therefore, this method is applicable to investigate the crystallization behavior of many systems, such as the crystallization of homopolymers forming a domain structure in immiscible polymer blends ${ }^{34}$ or confined crystallization in nanoporous alumina systems. ${ }^{39,40}$ 


\section{CONCLUSIONS}

We measured the crystallization process of a crystallineamorphous diblock copolymer, poly( $\varepsilon$-caprolactone)-blockpolybutadiene (PCL- $b$-PB), by using DSC and dynamic mechanical methods as a function of the crystallinity of PCL blocks. This system has spherical domains consisting of PCL blocks surrounded by PB matrices, and the crystallization of PCL blocks is completely confined within the domains. Following conclusions were obtained from this study.

1. DSC results showed that the crystallization behavior of PCL blocks was substantially different from that of PCL homopolymers, and similar to that usually observed in other spherically or cylindrically confined crystalline blocks, suggesting that the crystallization follows the first-order kinetics.

2. The result of dynamic mechanical measurements can be satisfactorily explained by the model assuming that each domain crystallizes immediately to yield rigid spheres, which is consistent with the conclusion derived by DSC measurements.

3. The dynamic mechanical measurement is one of the useful methods to investigate the crystallization process of spherically confined crystalline blocks.

Acknowledgment. This work was supported in part by NEDO (New Energy and Industrial Technology Development Organization) launched in 2001 and also by Grants-in-Aid for Scientific Research on Basic Areas (B) (No. 17350102) from the Ministry of Education, Science, Sports, and Culture of Japan. The SR-SAXS measurement has been performed under the approval of Photon Factory Advisory Committee (No. 2006G078).

Received: June 16, 2008 Accepted: July 13, 2008 Published: August 28, 2008

\section{REFERENCES}

1. Y. L. Loo and R. A. Register, "Developments in Block Copolymer Science and Technology," I. W. Hamley, Ed., Wiley, 2004.

2. A. J. Müller, V. Balsamo, and M. L. Arnal, Adv. Polym. Sci., 190, 1 (2005).

3. S. Nojima, K. Kato, S. Yamamoto, and T. Ashida, Macromolecules, 25, 2237 (1992).

4. P. Rangarajan, R. A. Register, L. J. Fetters, W. Bras, S. Naylor, and A. J. Ryan, Macromolecules, 28, 4932 (1995).

5. Y. L. Loo, R. A. Register, and A. J. Ryan, Phy. Rev. Lett., 84, 4120 (2000).

6. S. Nojima, M. Toei, S. Hara, S. Tanimoto, and S. Sasaki, Polymer,
43, 4087 (2002).

7. P. A. Weimann, D. A. Hajduk, C. Chu, K. A. Chaffin, J. C. Brodil, and F. S. Bates, J. Polym. Sci., Part B: Polym. Phys., 37, 2053 (1999).

8. H. L. Chen, S. C. Hsiao, T. L. Lin, K. Yamauchi, H. Hasegawa, and T. Hashimoto, Macromolecules, 34, 671 (2001).

9. Y. L. Loo, R. A. Register, A. J. Ryan, and G. T. Dee, Macromolecules, 34, 8968 (2001).

10. Y. L. Loo, R. A. Register, and A. J. Ryan, Macromolecules, 35, 2365 (2002).

11. A. J. Müller, V. Balsamo, M. L. Arnal, T. Jakob, H. Schmalz, and V. Abetz, Macromolecules, 35, 3048 (2002).

12. H. Schmalz, A. Knoll, A. J. Müller, and V. Abetz, Macromolecules, 35, 10004 (2002).

13. Y. Y. Huang, H. L. Chen, H. C. Li, T. L. Lin, and J. S. Lin, Macromolecules, 36, 282 (2003).

14. A. Röttele, T. Thurn-Albrecht, J. U. Sommer, and G. Reiter, Macromolecules, 36, 1257 (2003).

15. V. Balsamo, C. U. Navarro, and G. Gil, Macromolecules, 36, 4507 (2003).

16. A. T. Lorenzo, M. L. Arnal, A. J. Müller, A. B. Fierro, and V. Abetz, Eur. Polym. J., 42, 516 (2006).

17. R. V. Castillo, M. L. Arnal, A. J. Müller, I. W. Hamley, V. Castelletto, H. Schmalz, and V. Abetz, Macromolecules, 41, 879 (2008).

18. G. Reiter, G. Castelein, J. U. Sommer, A. Röttele, and T. ThurnAlbrecht, Phys. Rev. Lett., 87, 226101 (2001).

19. Q. Guo, R. Thomann, W. Gronski, R. Staneva, R. Ivanova, and B. Stühn, Macromolecules, 36, 3635 (2003).

20. M. V. Massa, J. L. Carvalho, and K. D. Veress, Phy. Rev. Lett., 97, 247802 (2006).

21. J. K. Hobbs and R. A. Register, Macromolecules, 39, 703 (2006).

22. L. Kailas, C. Vasilev, J. N. Audinot, H. N. Migeon, and J. K. Hobbs, Macromolecules, 40, 7223 (2007).

23. S. Nojima, D. Wang, and T. Ashida, Polym. J., 23, 1473 (1991).

24. S. Nojima, H. Nakano, Y. Takahashi, and T. Ashida, Polymer, 35, 3479 (1994).

25. S. Nojima, H. Tsutsui, M. Urushihara, W. Kosaka, N. Kato, and T. Ashida, Polym. J., 18, 451 (1986).

26. S. Nojima, K. Kato, M. Ono, and T. Ashida, Macromolecules, 25, 1922 (1992).

27. M. Akaba and S. Nojima, Polym. J., 38, 559 (2006).

28. V. Crescenzi, G. Manzini, G. Calzolari, and C. Borri, Eur. Polym. J., 8, 449 (1972).

29. K. Nitta and A. Tanaka, Polymer, 42, 1219 (2001).

30. H. Marand and Z. Huang, Macromolecules, 37, 6492 (2004).

31. T. Sakurai, Y. Ohguma, and S. Nojima, Polym. J., 40, 971 (2008).

32. B. Wunderlich, "Macromolecular Physics Volume 2, Crystal Nucleation, Growth, Annealing," Academic Press, New York, 1976.

33. M. V. Massa and K. D. Veress, Phy. Rev. Lett., 92, 255509 (2004).

34. S. Nojima, Y. Ohguma, S. Namiki, T. Ishizone, and K. Yamaguchi, Macromolecules, 41, 1915 (2008).

35. J. C. Halpin, J. Compos. Mater., 3, 732 (1969).

36. J. C. Halpin and J. L. Kardos, Polym Eng. Sci., 16, 344 (1976).

37. A. Dufresne, J. Y. Cavaille, and W. Helbert, Macromolecules, 29, 7624 (1996).

38. M. Takayanagi, J. Polym Sci., C5, 113 (1964).

39. M. Steinhart, P. Göring, H. Dernaika, M. Prabhukaran, U. Gösele, E. Hempel, and T. Thurn-Albrecht, Phys. Rev. Lett., 97, 027801 (2006)

40. E. Woo, J. Huh, Y. G. Jeong, and K. Shin, Phys. Rev. Lett., 98, 136103 (2007) 